\title{
Influence of the amount of permanent magnet material in fractional-slot permanent magnet synchronous machines
}

\author{
Peter Sergeant and Alex Van den Bossche
}

\begin{abstract}
The efficiency of permanent magnet synchronous machines (PMSM) with outer rotor and concentrated windings is investigated as a function of the mass of magnets used, keeping the power, volume and mechanical air gap thickness constant. In order to be useful for electric vehicle motors and wind turbine generators, the efficiency is computed in a wide speed and torque range, including overload. For a given type and amount of magnets, the geometry of the machine and the efficiency map are computed by analytical models and finite element models, taken into account iron loss, copper loss, magnet loss and pulse width modulation loss. The models are validated by experiments. Furthermore, the demagnetization risk and torque ripple are studied as a function of the mass of magnets in the machine. The effect of the mass of magnets is investigated for several soft magnetic materials, several combinations of number of poles and number of stator slots, and for both rare earth $(\mathrm{NdFeB})$ magnets and ferrite magnets. It is observed that the amount of permanent magnet material can vary in a wide range with a minor influence on the efficiency, torque density, and torque ripple and with a limited demagnetization risk.
\end{abstract}

Index Terms-Permanent magnet machines, Brushless machines, Finite element methods, Magnetic losses, Magnetic materials, Pulse width modulation, Variable speed drives

\section{NOMENCLATURE}

Nominal speed

Stator outer radius

Number of stator slots

Turns per winding

Yoke saturation flux density

Magnet radial thickness

Magnet permeability

Magnet-to-pole pitch ratio
Rotor yoke thickness

$\begin{array}{lll}N_{\text {nom }} & \text { Nominal power } & P_{\text {nom }} \\ r_{\mathrm{so}} & \text { Tooth width } & w_{\text {tooth }} \\ N_{\mathrm{t}} & \text { Stack length } & L_{\mathrm{s}} \\ N_{\mathrm{w}} & \text { Rotor outer radius } & r_{\mathrm{ro}} \\ B_{\mathrm{tm}} & \text { Air gap thickness } & t_{\mathrm{a}} \\ t_{\mathrm{m}} & \text { Magnet width } & w_{\mathrm{m}} \\ \mu_{\mathrm{m}} & \text { Magnet remanence } & B_{\mathrm{r}} \\ \alpha_{\mathrm{p}} & \text { Number of poles } & 2 p \\ t_{\mathrm{ry}} & \text { Phase resistance } & R_{\mathrm{ph}}\end{array}$

\section{INTRODUCTION}

Fractional-slot concentrated-winding permanent magnet synchronous machines (PMSM's) have become popular because of their high torque density, high efficiency, good fault

Manuscript received Jan. 5, 2013. Accepted for publication March 26, 2013 Copyright (c) 2009 IEEE. Personal use of this material is permitted. However, permission to use this material for any other purposes must be obtained from the IEEE by sending a request to pubs-permissions@ieee.org

Corresponding author: P. Sergeant (Peter.Sergeant@UGent.be). This work was supported by the research Fund of University College Ghent and FWO projects 3G011013 and 3G008313. We thank OCAS for the magnetic material characteristics.

P. Sergeant and A. Van den Bossche are with the Dept. Electrical Energy, Systems and Automation of Ghent University, St-Pietersnieuwstraat 41, B9000 Gent, Belgium. P. Sergeant is also with the Research group Electrical Energy of Ghent University, V. Vaerwyckweg 1, B-9000 Gent, Belgium tolerance, a high slot fill factor, and separated windings with short end turns. These machines have a lot of opportunities and challenges, described in [1]. A review of design issues and techniques for these machines is given in [2]. Many aspects of the machine were investigated, such as the several combinations of number of poles and number of stator slots for the concentrated windings [3], or the optimal winding layout [4]. The paper [1] also compares double layer and single layer windings. An example of a surface PMSM with twolayer concentrated winding is given by Di Gerlando in [5].

A lot of papers deal with rotor losses in the considered type of machines, and give methods to compute them. For example [6] gives a general method for several slot/pole configurations. Polinder [7] studies losses in the solid back iron of PMSM with fractional slot windings. Atallah presented an analytical model to compute magnet loss [8], and Ede proposed a computationally efficient 3D numerical method to compute the magnet loss [9].

An aspect of fractional-slot concentrated-winding PMSM's that is less investigated, is how much the amount of magnets can be reduced, and how this affects the global machine design and performance. As the price of rare earth magnets is high, PMSM's with small amount of magnets become interesting, on condition that their efficiency and torque density remain high. It is known that very powerful and light permanent magnet machines can be made when a lot of PM material can be used: for example the slotless brushless DC PMSM of [10] has two concentric rotors, both of them completely covered with a thick layer of $\mathrm{NdFeB}$ magnets in Halbach array. Alternatives are investigated to reduce the required amount of permanent magnets, or even to have motors without magnets [11]. Nevertheless, [12] compared caged induction, reluctance, and PM motor technologies for the more electric aircraft, concluding that three-phase permanent magnet machines may still be the favorite choice.

Therefore, we investigate the impact of the amount of magnets and the magnetic material grade in the stator of the PMSM on the efficiency, keeping the machine volume and torque density constant. Here, we consider not only the efficiency at nominal speed $N_{\text {nom }}$ and torque $T_{\text {nom }}$, but also the average efficiency in the speed range $0.25-1.50 \times N_{\text {nom }}$ and torque range $0.25-1.50 \times T_{\text {nom }}$. A number of effects of reducing the amount of magnets can be found in [13]. However, several aspects were not considered such as the effect of the number of stator slots and rotor poles, the demagnetization risk, and 
the torque ripple.

In the following paragraphs, the influence of magnet mass in the design of fractional slot PMSM's is studied, taking into account the above mentioned aspects and design considerations of [4] and [14]. In addition, several modelling techniques exist, such as magnetic equivalent network based techniques [15], or exact analytical models for a surface PMSM [16]. We choose a quite simple analytical model for the rough design, followed by a more complex analysis with Finite Element Models (FEM) to predict the machine performance accurately. The analysis is limited to surface-mounted PMSM machines. A performance comparison between surface-mounted and interior PM motor drives is made in [17] for an electric vehicle application, showing that both types can be useful. An experimental validation of the models is done as well.

\section{Methodology TO INVESTIGATE THE INFLUENCE OF THE MAGNET THICKNESS AND THE MAGNETIC MATERIAL}

The methodology has an analytical part to design the machine and then a FEM part for accurate computation of the efficiency. The effect of three design input parameters is studied: 1) the radial magnet thickness $t_{\mathrm{m}}, 2$ ) the soft magnetic material grade in the stator iron, and 3) the combination of number of pole pairs $p$ and stator slots $N_{\mathrm{t}}$. For each combination of these three parameters, the machine is designed as explained further and the efficiency map is computed. In the methodology, the following constraints are applied in order to have a fair comparison of the several machines:

- The nominal power, supply voltage and nominal speed are fixed.

- The air gap thickness is fixed for mechanical reasons.

- The rotor yoke has a minimum thickness for mechanical reasons.

- The outer diameter and stack length are fixed so that the volume and active mass of the different machine configurations remain approximately constant.

The methodology is sufficiently general, and valid for all permanent magnet synchronous machines with surface magnets in variable speed drives. We apply it to three-phase radial flux machines, but the methodology could also be applied to axial flux machines with concentrated windings such as in



(a)

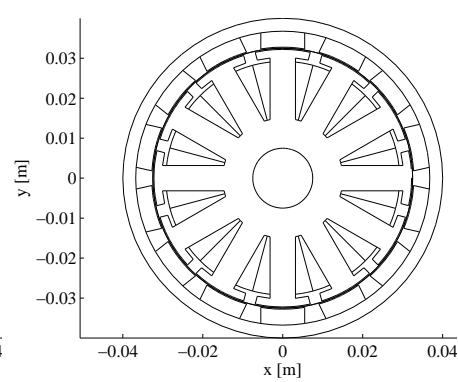

(b)
Fig. 1. The motor geometry in case of "extremely thin" magnets in (a) and "extremely thick" magnets in (b). The machine with thin magnets has much smaller stator teeth and thinner back iron than the motor with thick magnets). The outer diameter is always $80 \mathrm{~mm}$, and also the mechanical power and air gap thickness are equal for all machines.
[18], or to six-phase double-star armature windings such as in [19].

We illustrate the methodology for a $1.5 \mathrm{~kW}$ outer rotor PMSM with fixed outer diameter $(80 \mathrm{~mm})$, fixed stack length (40 mm) and concentrated stator windings. The air gap thickness is fixed to $0.55 \mathrm{~mm}$ and the rotor yoke has a minimum thickness of $1.3 \mathrm{~mm}$. Fig. 1 shows typical geometries for several values of the input parameter $t_{\mathrm{m}}$ and Table I gives dimensions. Based on the three input parameters, the number of turns, the air gap diameter, tooth width, and rotor yoke thickness are determined. The effects of the flux weakening capability of the machine are not considered.

TABLE I

PROPERTIES OF THE BRUSHLESS MOTORS. WHEN A RANGE IS GIVEN FOR A PARAMETER, THIS PARAMETER IS COMPUTED BASED ON THE INPUT PARAMETERS $t_{\mathrm{m}}$, MATERIAL GRADE, $p$, AND $N_{\mathrm{t}}$. THE COLUMN

“EXPERIMENTAL" REFERS TO THE DIMENSIONS OF THE EXPERIMENTAL MACHINE IN SECTION V.

\begin{tabular}{llrrr}
\hline \multicolumn{1}{c}{ Property } & & \multicolumn{2}{c}{ Simulation Experimental } \\
\hline General Nominal speed & $N_{\text {nom }}$ & $4500 \mathrm{rpm}$ & $4500 \mathrm{rpm}$ \\
& & $100 \mathrm{~V}$ & $100 \mathrm{~V}$ \\
& DC bus voltage & $P_{\mathrm{nom}}$ & $1.5 \mathrm{~kW}$ & $1.5 \mathrm{~kW}$ \\
\hline Nominal power & $r_{\mathrm{so}}$ & $r_{\mathrm{ro}}-t_{\mathrm{ry}}-t_{\mathrm{m}}-t_{\mathrm{a}}$ & $34.2 \mathrm{~mm}$ \\
\hline Stator & Outer radius & $w_{\text {tooth }}$ & $3-10 \mathrm{~mm}$ & $3.9 \mathrm{~mm}$ \\
& Copper fill factor & $L_{\mathrm{s}}$ & $40 \mathrm{~mm}$ & $40 \mathrm{~mm}$ \\
Tooth width & $N_{\mathrm{t}}$ & $9-18$ & 12 \\
Stack length & $N_{\mathrm{w}}$ & $1-100$ & 10 \\
Number of slots & $r_{\mathrm{ro}}$ & $40 \mathrm{~mm}$ & $40 \mathrm{~mm}$ \\
& Turns per winding & $2 p$ & $6-16$ & 14 \\
Rotor & Outer radius & $t_{\mathrm{a}}$ & $0.55 \mathrm{~mm}$ & $0.55 \mathrm{~mm}$ \\
& Number of poles & 0.89 & 0.71 \\
Air gap thickness & $\alpha_{\mathrm{p}}$ & $0.6-5 \mathrm{~mm}$ & $3.55 \mathrm{~mm}$ \\
Magnet-to-pole pitch ratio & $t_{\mathrm{m}}$ & $\alpha_{\mathrm{p}} \pi\left(r_{\mathrm{ro}}-t_{\mathrm{ry}}\right)$ & $11 \mathrm{~mm}$ \\
Magnet radial thickness & $w_{\mathrm{m}}$ & $p$ & $1.05 \mu_{0}$ & $1.05 \mu_{0}$ \\
Magnet width & $\mu_{\mathrm{m}}$ & $1.1 \mathrm{or} 0.35 \mathrm{~T}$ & $1.1 \mathrm{~T}$ \\
Magnet permeability & $B_{\mathrm{r}}$ & $1.65 \mathrm{~T}$ & $1.65 \mathrm{~T}$ \\
Magnet remanence & $B_{\mathrm{tm}}$ & $20 \mathrm{~mm}$ & $20 \mathrm{~mm}$ \\
Yoke saturation flux density & $(1)$ & & \\
Additional axial yoke length & $L_{\mathrm{se}}$ & $1.3-3.2 \mathrm{~mm}$ & $1.65 \mathrm{~mm}$ \\
Iron yoke thickness & $t_{\mathrm{ry}}$ & & &
\end{tabular}

(1) In analytical model only

\section{A. Determining geometry parameters by an analytical model}

For a given magnet thickness $t_{\mathrm{m}}$, number of poles $p$, number of slots $N_{\mathrm{t}}$ and stator magnetic material grade, the machine geometry is determined so that the iron in the machine is used efficiently, i.e. that the iron has a high flux density without being completely saturated. The details of the design procedure are given in Appendix 1. In comparison to [13], the air gap field is computed more accurately - as it takes into account curvature of the rotor - based on an analytical solution of the air gap field: it is computed based on [20] instead of [21]. In addition to [13], several combinations of number of poles and number of stator slots are considered by the analytical model, and also the short circuit current, and the demagnetization risk are computed.

The geometry is totally different for thin (Fig. 1a) and thick magnets (Fig. 1b). For thin magnets:

- The stator teeth have a small width because of the low air gap flux density, due to the fixed air gap thickness 
- The air gap diameter is larger for the same outer diameter

- The number of turns is high to keep the same Emf as in machines with thicker magnets (fixed DC bus voltage)

The analytical design is fast, but has drawbacks:

- The thicknesses of the stator teeth and the rotor yoke are calculated based on a "saturation" flux density of $1.65 \mathrm{~T}$, which is typical for silicon steel laminations.

- The losses consist of only the copper loss and the stator iron loss. Moreover, the stator iron loss is computed based on the flux density norm and the frequency, not on the realistic waveforms of the flux density. It is assumed that the copper loss is not dependent on the speed and that the iron loss is not dependent on the torque.

- We neglect losses in rotor yoke, magnets and bearings, and additional iron losses by the leakage fluxes.

The cogging torque was not computed by the analytical model, but it can be computed like in [22], which presents four analytical models that allow to predict the cogging torque in surface-mounted PMSM machines.

\section{B. Accurate efficiency evaluation by Finite element method}

For a given $t_{\mathrm{m}}$ and stator magnetic material grade, a 2D FEM is made with the geometry as designed by the analytical approach. The FEM is a conventional 2D static magnetic vector potential problem. It is executed for several position angles of the rotor, in order to record:

- Torque to evaluate torque ripple and mechanical power

- Flux density pattern in stator iron to compute iron loss

- Flux density pattern in the magnets to compute the induced eddy current losses via a coupled 2D-3D approach

Two possible geometries are shown in Fig. 1. The FEM has the following more accurate features in order to compute the losses by loss models, explained in the next paragraphs:

- Realistic $B H$-curve of all considered magnetic materials

- Realistic iron loss computation by a time domain loss model coupled to 2D FEM (paragraph IV-A)

- Computation of additional losses due to time harmonics from Pulse Width Modulation (PWM); these losses are computed in the magnets and rotor back iron (paragraph IV-C) and in the stator iron (paragraph IV-D)

- Computation of losses in the magnets caused by reluctance effects and mmf space harmonics, via a coupled 2D-3D FEM approach (paragraph IV-E)

\section{COMPUTATION OF LOSS TERMS}

\section{A. Iron losses}

In [23], an overview is given to compute iron losses, based on the loss separation theory.

In the analytical model, we assume sinusoidal induction waveforms, and we use the loss equation in the frequency domain. The loss per cycle consists of hysteresis loss, classical loss and excess loss:

$$
\begin{aligned}
W_{\mathrm{fe}}(B, f) & =W_{\mathrm{hy}}+W_{\mathrm{cl}}+W_{\mathrm{ex}} \\
& =a B^{\alpha}+b B^{2} f+c B(\sqrt{1+d B f}-1)
\end{aligned}
$$

where $f$ is the electrical frequency. The coefficients $a, b, c$, and $d$ are to be determined by fitting based on Epstein frame measurements: details are given in Appendix 2. The nominal frequency $f_{\text {nom }}$ of the considered machines with 6 to 16 poles is 225 to $600 \mathrm{~Hz}$ for $N_{\text {nom }}=4500 \mathrm{rpm}$. The result can be seen in Fig. 2 for one of the four considered materials.

In the Finite Element Model, the time domain loss model is used as it is more accurate in case of non-sinusoidal waveforms [23]. A similar equation as (1) computes the loss $W_{\mathrm{fe}}$ for a given waveform $B(t)$ :

$$
\begin{aligned}
W_{\mathrm{fe}}(B, t)= & W_{\mathrm{hy}}+b^{\prime} \int_{0}^{T} \dot{B}(t)^{2} \mathrm{~d} t+ \\
& c^{\prime} \int_{0}^{T}|\dot{B}(t)|\left(\sqrt{1+d^{\prime}|\dot{B}(t)|}-1\right) \mathrm{d} t
\end{aligned}
$$

Here, $B(t)$ is obtained by $2 \mathrm{D}$ FEM simulations at different time instants, i.e. different rotor positions. The procedure is explained in Appendix 2.

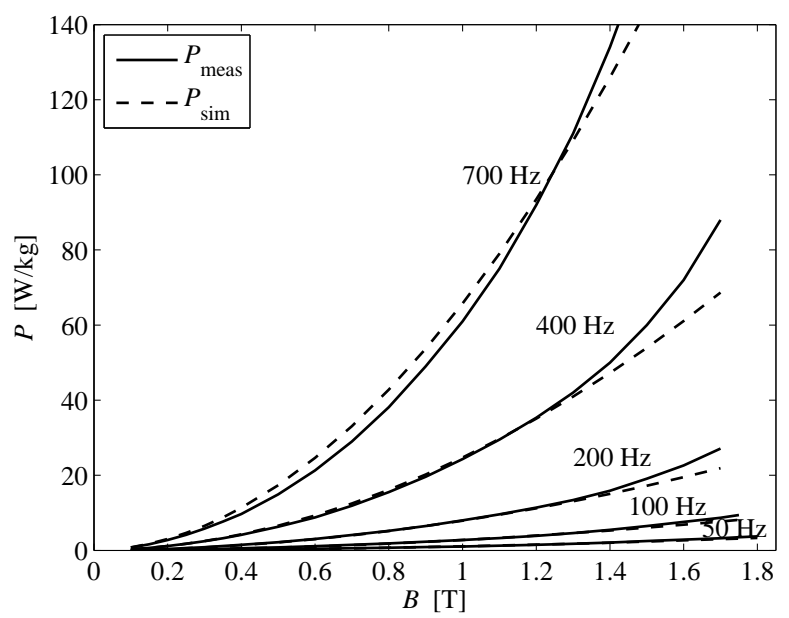

Fig. 2. Specific losses of the material M250-50A, obtained by measurements on Epstein frame and by simulations from the loss model

The accurate loss computation - time domain loss model combined with the FEM - gives lower losses for low current - see Fig. 3 - because the magnetic flux density is somewhat lower than the $1.65 \mathrm{~T}$ of the analytical model in a large part of the geometry. For higher current, the accurate loss computation predicts higher losses, partly because the flux density reaches higher values, but also because the waveforms of the flux density are not sinusoidal.

For all magnetic materials compared, Fig. 4 shows that iron losses in the machine increase slightly with the magnet thickness $t_{\mathrm{m}}$. The amount of iron remains almost constant (thicker teeth but smaller stator radius), but the average flux density increases slightly with $t_{\mathrm{m}}$.

\section{B. Copper loss}

The copper loss is found from the wire resistance computed in the analytical model (Appendix 1), and the value of the injected current. For increasing $t_{\mathrm{m}}$, the number of turns per winding decreases but the available copper section decreases too. Therefore, the copper loss has no clear trend with increasing $t_{\mathrm{m}}$ : at nominal load for the machine with $2 p=14$, it first 


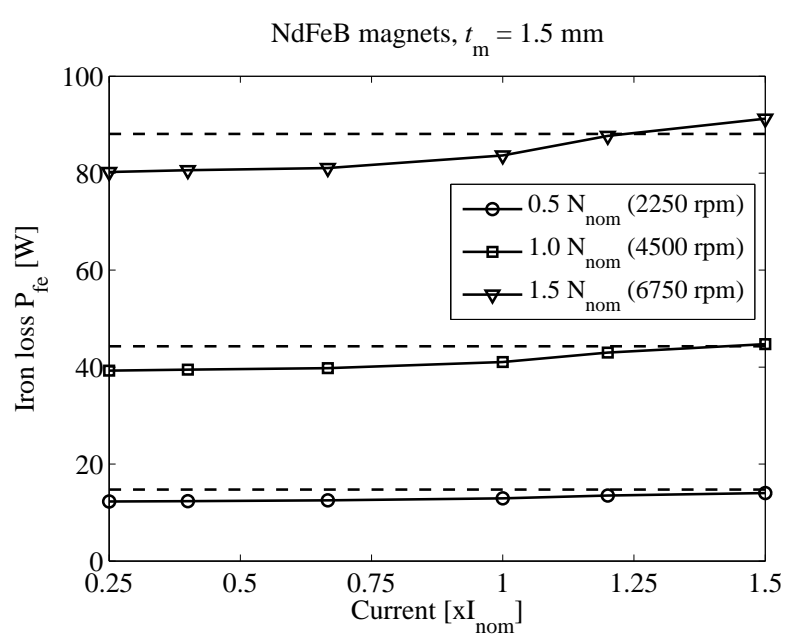

Fig. 3. Iron loss for the machine with $1.5 \mathrm{~mm}$ magnet thickness and M235$35 \mathrm{~A}$, as a function of the load current. The dashed lines show the iron loss prediction of the analytical model, which does not depend on the load current.

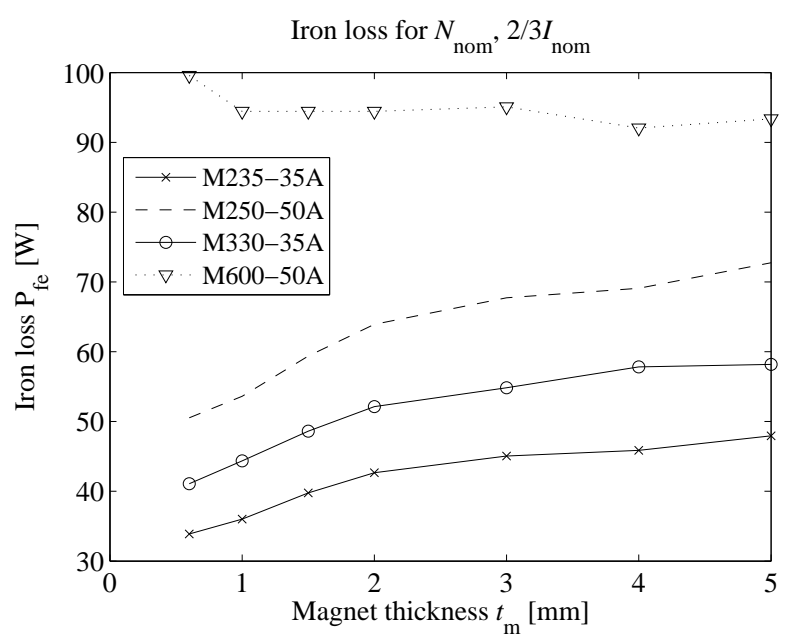

Fig. 4. Iron loss for all materials, at nominal speed and $10 \mathrm{~A}\left(2 / 3 I_{\text {nom }}\right)$

decreases from $46 \mathrm{~W}$ for $t_{\mathrm{m}}=0.6 \mathrm{~mm}$ to $36 \mathrm{~W}$ at $t_{\mathrm{m}}=2 \mathrm{~mm}$ and then increases to $50 \mathrm{~W}$ for $t_{\mathrm{m}}=5 \mathrm{~mm}$.

\section{Pulse width modulation (PWM) loss in the magnets}

In [24], it is shown that the eddy-current loss in a magnet is mainly produced by the carrier harmonics of the inverter.

To compute losses caused by PWM, a 2D time harmonic FEM was made with the same geometry as in paragraph III-B. The magnet remanence was set to zero, and the PWM frequency was applied in the stator windings. In the considered brushless DC machine, two windings are in series, so that both phases see PWM pulses with only half of the DC bus voltage. The current in the third phase is set to zero. In this model, the rotor is not rotating. The applied frequency is the carrier frequency (5 or $15 \mathrm{kHz}$ ) of the PWM and harmonics. The PWM loss in the rotor is the summation of losses for the carrier frequency and harmonics, computed in both the magnets and the rotor back iron.

Fig. 5a shows the PWM loss in the rotor of the different machines as a function of the magnet thickness. (a)
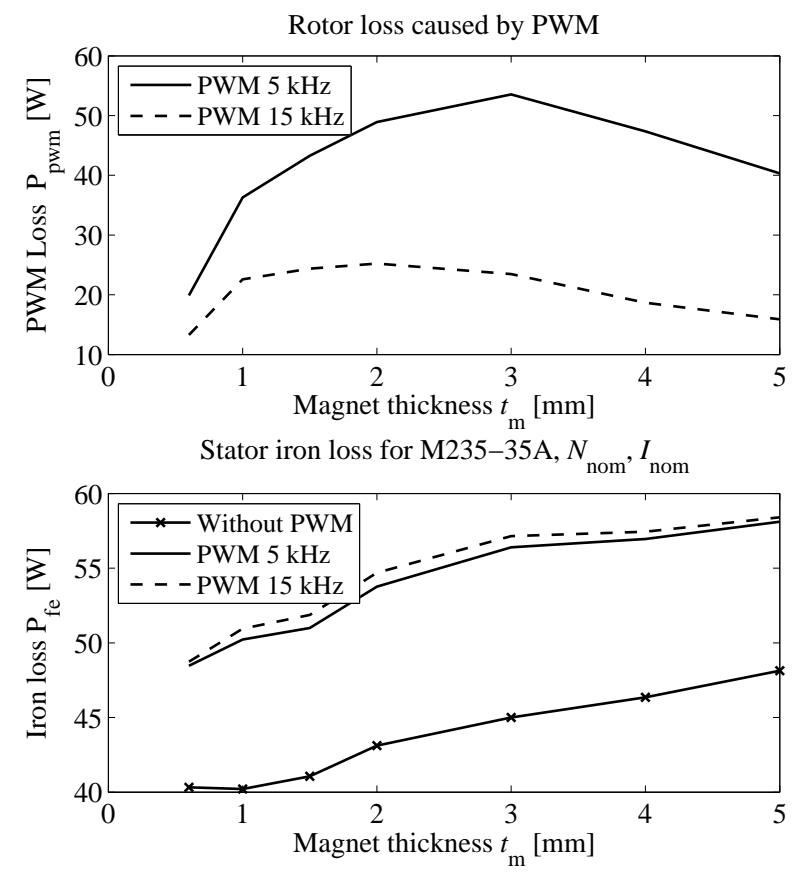

Fig. 5. Pulse width modulation loss (a) in the rotor magnets and rotor back iron and (b) in the stator iron. In (b), the curves "PWM 5kHz" and "PWM $15 \mathrm{kHz}$ " represent the total iron loss including PWM.

The loss is much higher at $5 \mathrm{kHz}$ than at $15 \mathrm{kHz}$, because the peak-to-peak flux variation caused by PWM with constant DC bus voltage is higher at $5 \mathrm{kHz}$. As the magnets are axially much longer than their width, the 2D-model will only slightly overestimate the magnet loss. The figure shows that for small magnet thickness $\left(t_{\mathrm{m}} \leq 2 \mathrm{~mm}\right)$, the PWM loss increases. The reason is that with increasing $t_{\mathrm{m}}$, the number of turns in the stator windings decreases, so that the constant DC bus voltage causes larger flux variations and larger losses in thicker magnets. For thicker magnets $\left(t_{\mathrm{m}} \geq 3 \mathrm{~mm}\right)$, the number of turns is not changing any more with the magnet thickness. Here, the PWM loss in the rotor starts decreasing for the following reason. Because of the larger distance to the rotor back iron, more flux lines close between adjacent stator teeth or in the air gap, causing less flux variation and loss in each magnet.

\section{Pulse width modulation (PWM) loss in the stator iron}

For computing the PWM losses in the stator iron lamination, one of the three methods of [25] can be used. In the FEM of paragraph III-B, the time domain iron loss model is used. If PWM is included in the supply waveforms, then this model automatically includes PWM loss, such as in method 1 of [25]. However, this requires a very small time step in the simulation. Therefore, we keep the iron losses without PWM as presented in section IV-A and we try to estimate the extra loss caused by PWM in the following way:

- The hysteresis loss remains the same. This is valid if no minor loops are created in the hysteresis cycle: the hysteresis loss then depends on the peak induction values 
only. According to [26], when three level modulation techniques are used, minor loop losses can be neglected.

- The classical losses are obtained by superposition of the already computed $P_{\mathrm{cl}}(t)$, and the additional classical losses $P_{\mathrm{cl}, \text { ad }}(t)$ caused by the PWM. This method is based on [27], where it is assumed that, under PWM supply, the higher order flux density harmonics do not influence the magnetic work conditions imposed by the fundamental component of the flux density. The iron losses including PWM are estimated by the addition of iron losses without PWM and the iron losses of all PWM harmonics. The iron loss of one PWM harmonic is computed from the induction waveforms obtained by the same time-harmonic FEM as in paragraph IV-C and loss equation (1).

- The additional excess loss is computed like in (1), but for the PWM frequency and induction amplitude.

For the considered machines, it was found that the additional loss in the iron due to PWM is not negligible compared to the iron loss without PWM: Fig. 5b shows for example for 1.5 $\mathrm{mm}$ thick magnets an iron loss increase from 41 to $51 \mathrm{~W}$.

\section{E. Magnet loss caused by space harmonics}

Computing the magnet loss via a transient 3D FEM of the whole machine is very time consuming. Therefore, several empirical calculation methods are developed and compared in [28] and [29]. However, we implemented the numerical method of Ede [9], which couples a 2D FEM and a 3D FEM: from the static 2D FEM of the complete machine, which is run for several rotor positions, the magnetic flux density vector is recorded in a grid of points in the magnet, as a function of time (or rotor position). The time derivative of this flux density vector is enforced as a source term in a 3D FEM of one magnet only. The $3 \mathrm{D}$ eddy current problem in the magnet is:

$$
\nabla \times \mathbf{E}=-\frac{\partial \mathbf{B}}{\partial t} \text { with } \mathbf{J}=\sigma \mathbf{E}
$$

If we assume that the magnet currents are resistance limited, i.e. that their influence on the inducing magnetic field distribution is negligible, then the 3D eddy current problem in (3) or (4) is equivalent to a linear magnetostatic field problem:

$$
\begin{array}{lll}
\nabla \times \mathbf{E}=-\frac{\partial \mathbf{B}}{\partial t} & \text { with } & \mathbf{J}=\sigma \mathbf{E} \\
\nabla \times \mathbf{H}_{\mathrm{m}}=\mathbf{J}_{\mathrm{m}} & \text { with } & \mathbf{B}_{\mathrm{m}}=\mu \mathbf{H}_{\mathrm{m}}
\end{array}
$$

We solve the magnetostatic problem, but the source term is $-\partial \mathbf{B} / \partial t$ instead of $\mathbf{J}_{\mathrm{m}}$, the permeability term becomes a conductivity, and the solution $\mathbf{B}_{\mathrm{m}}$ is to be interpreted as current density. To obtain the source term $-\partial \mathbf{B} / \partial t$ in the $3 \mathrm{D}$ model, the flux density waveforms $\mathbf{B}(t)$ are recorded by the 2D model of the complete machine, and then derived to time. Fig. 6a. shows an example of the current density distribution.

Fig. $6 \mathrm{~b}$ shows that the magnet loss at nominal speed is rather small compared to the iron loss at nominal speed. The magnet loss rescales quadratically with the speed for frequencies where skin effect is negligible. It strongly increases with the load current, especially for thin magnets. This is explained by the higher number of turns of machines with thin magnets, so that a larger (non-sinusoidal) $\mathrm{mmf}$ is present in the slots.

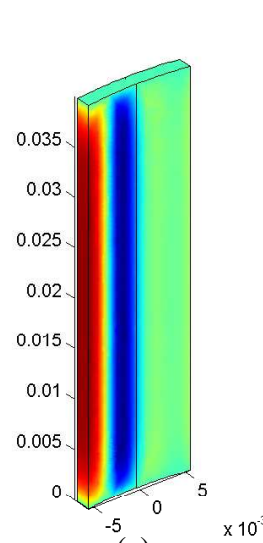

(a)

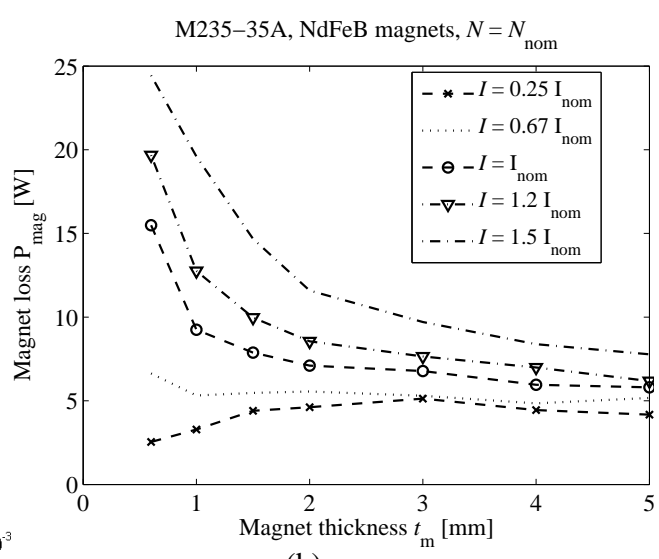

(b)
Fig. 6. (a) Distribution of the vertical component of the current density in a $3 \mathrm{~mm}$ thick magnet reveals the instantaneous position of a stator slot in front of the magnet; The scale ranges from $-4 \times 10^{4} \mathrm{~A} / \mathrm{m}^{2}$ to $5 \times 10^{4} \mathrm{~A} / \mathrm{m}^{2}$ (b) Losses in the magnets at nominal speed obtained by the coupled 2D-3D approach. The magnet loss increases significantly with the load current, as expected for fractional-slot concentrated winding machines.

\section{F. Efficiency maps and average efficiency}

The most important figure of the paper is Fig. 7, which shows the average efficiency over the speed range 0.25 $1.50 \times N_{\text {nom }}$ and torque range $0.25-1.50 \times T_{\text {nom }}$, for several magnet thicknesses and several soft magnetic materials, (a) by the analytical model and (b) by FEM.

Each point in Fig. 7 represents one machine. For each machine, the geometrical and electromagnetic properties are determined and the whole efficiency map is computed and averaged to one single value per machine in the figure.

Fig. 7 shows that for the considered machine and the considered material grades, the efficiency depends much more on the magnetic material than on the magnet thickness, if this thickness is chosen in a realistic range of $1.5-5 \mathrm{~mm}$. As the air gap is fixed $(0.55 \mathrm{~mm})$, very thin magnets are not optimal because the air gap flux density is too low. Moreover, thin magnets are prone to demagnetization (see section VI-C). As the outer machine diameter is fixed, very thick magnets are not optimal either because the increased rotor thickness and fixed outer rotor diameter cause a smaller air gap diameter. This requires a higher force per square meter air gap surface to produce the same torque. The decrease of the efficiency with the magnet thickness is very slow. Fig. $7 \mathrm{~b}$ shows that the magnet thickness can be reduced to about 1 $\mathrm{mm}$ without significantly reducing the efficiency. The optimal magnet thickness range is $1.5 \mathrm{~mm}-4 \mathrm{~mm}$.

Comparing the analytical model (Fig. 7a) with the FEM (Fig. 7b), the average efficiency of FEM is much lower because it includes losses in the rotor yoke and magnets (space harmonics and PWM), and PWM loss in the stator iron. Nevertheless, the conclusions and tendencies are the same for both methods, e.g. the optimal range for $t_{\mathrm{m}}$ and the efficiency difference between the several materials. Therefore, the conclusion is that the analytical model is useful for designing a good machine, but not to accurately predict its efficiency quantitatively.

Taking material M235-35A and $t_{\mathrm{m}}=1.5 \mathrm{~mm}$ results in the efficiency map of Fig. 8. The flux weakening region is not 


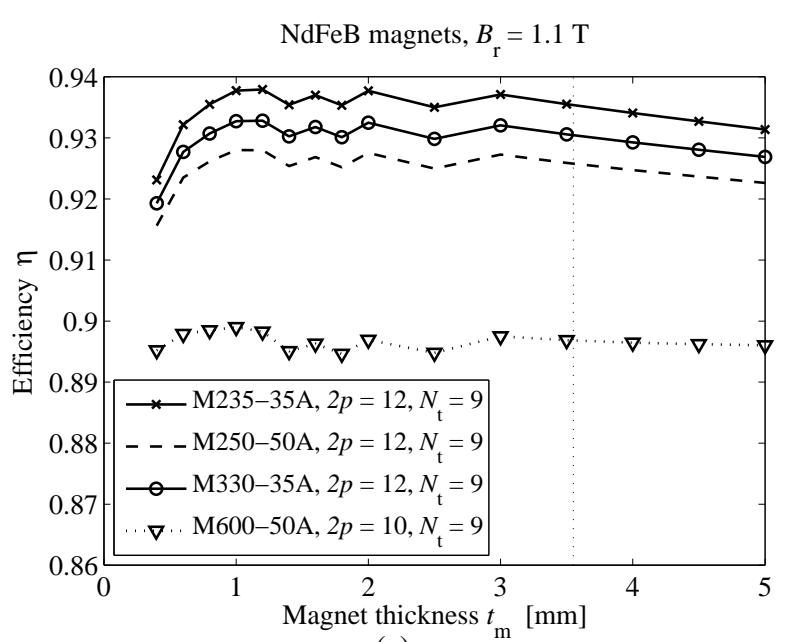

(a)

NdFeB magnets, $B_{\mathrm{r}}=1.1 \mathrm{~T}, 14$ poles, 12 teeth

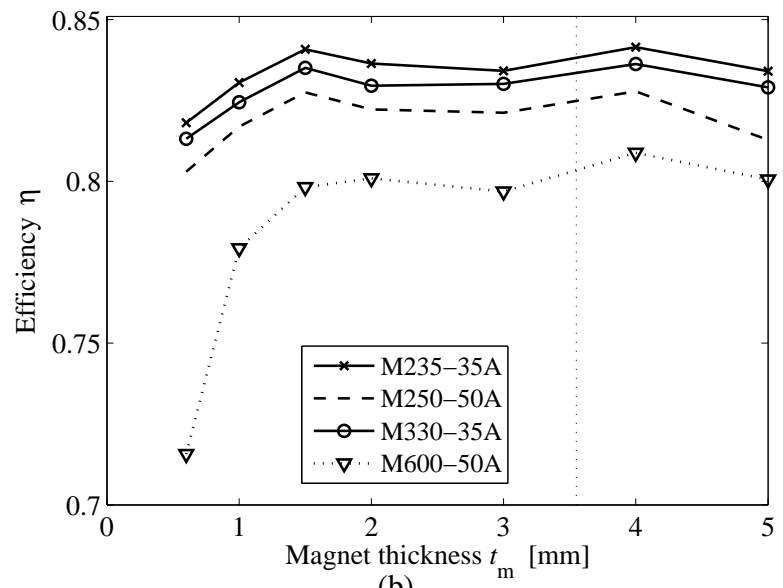

(b)

Fig. 7. Average efficiency of a PMSM in the speed range $0.25-1.50 \times N_{\text {nom }}$ and torque range $0.25-1.50 \times T_{\mathrm{nom}}$, as a function of the $\mathrm{NdFeB}$ magnet thickness $t_{\mathrm{m}}$ and the material grade, (a) analytical model, excluding PWM iron losses and rotor losses (b) FEM, including PWM iron losses and magnet losses. The vertical dashed line denotes the experimental machine. The discontinuities are caused by the round-off that forces the number of turns to an integer. Note that in (a) the number of stator slots and poles is chosen to be the one resulting in the highest efficiency, while it is chosen fixed in (b).

shown. Although the average efficiency in the considered load and speed range is only $84 \%$, a quite large speed-torque region including the nominal working point has over $90 \%$ efficiency. Fig. 7 shows that the magnets of the experimental machine are thicker than necessary for optimal efficiency.

The total efficiency for a machine with M235-35A material, $1.5 \mathrm{~mm}$ thickness at nominal current and speed is between 91 and 92\%: see Fig. 8. The total losses are $122 \mathrm{~W}$, consisting of copper loss $(37.4 \mathrm{~W})$, iron loss $(41.1 \mathrm{~W}$ plus $10.8 \mathrm{~W}$ extra PWM loss: see fig. 5), and rotor loss ( $8.8 \mathrm{~W}$ plus $24.3 \mathrm{~W}$ extra PWM loss: see Fig. 6).

\section{EXPERIMENTAL VALIDATION}

The computed efficiency is compared with measurements for the experimental machine with 14 poles, 12 stator slots, $t_{\mathrm{m}}=3.55 \mathrm{~mm}$ and details in Table I. In the experiment, two identical machines were used in back-to-back configuration. The first one is the motor under test, supplied with current

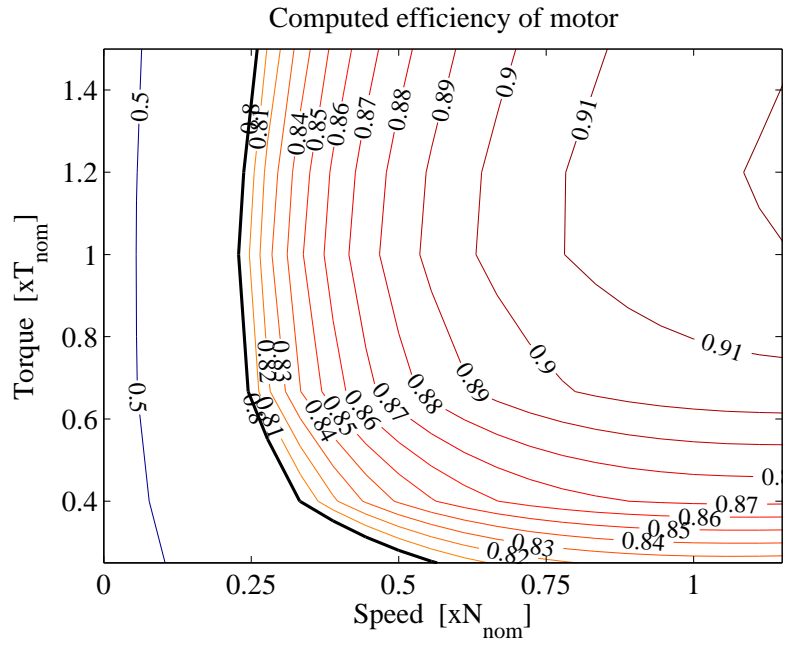

Fig. 8. Efficiency map of a PMSM with M235-35A, $2 p=14, N_{\mathrm{t}}=12$, and $\mathrm{NdFeB}$ magnets with $t_{\mathrm{m}}=1.5 \mathrm{~mm}$, obtained by FEM

blocks of 120 electrical degrees by the inverter with PWM. The second one was used as generator and loaded with almost identical current blocks. The electrical input power of the motor and output power of the generator were measured, and half of the difference was assumed to be the loss of each machine. The results are in Fig. 9. Notice that the windage and bearing losses are included in the measurements, but not in the simulations.

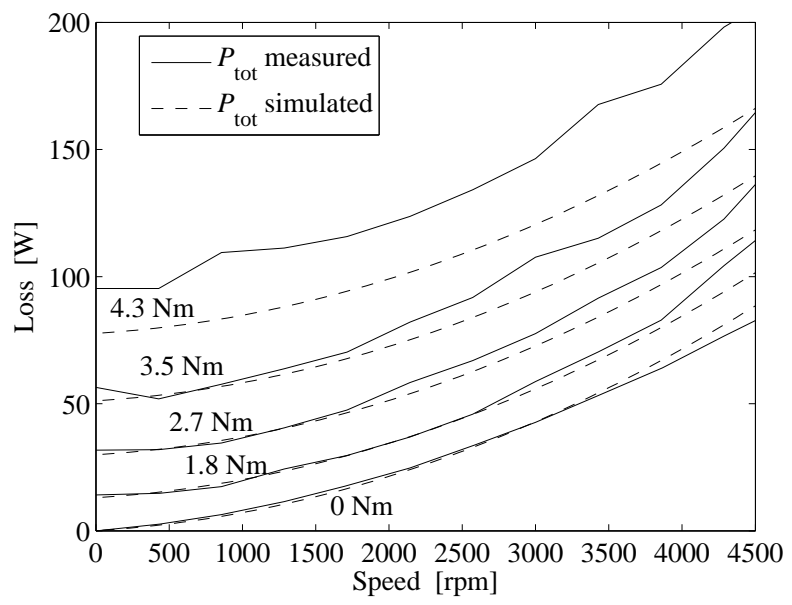

Fig. 9. Total losses for different speeds and torques of the $1.5 \mathrm{~kW}$ experimental machine. The losses become very high with increasing speed because of the high electrical frequency of $525 \mathrm{~Hz}$ at $N_{\text {nom }}=4500 \mathrm{rpm}$.

The computed no-load losses - the curve for $0 \mathrm{Nm}$ in Fig. 9 - are comparable with the measured losses. The fast increase of losses with speed makes clear that the iron loss is the dominant loss term, as a result of the rather high fundamental frequency of $525 \mathrm{~Hz}$ at nominal speed, even if $0.35 \mathrm{~mm}$ thin laminations are used (material M330-35A).

Under load conditions, the correspondence between measurements and simulations is good for low speed and low torque. For high speed and torque, the measured loss is higher than simulated, probably because in these working points with high losses, the temperature increased significantly in the machine. This results in lower magnet flux and more 
copper wire resistance, hence more losses. The measured and computed efficiency map of the experimental machine are shown in Fig. 10.

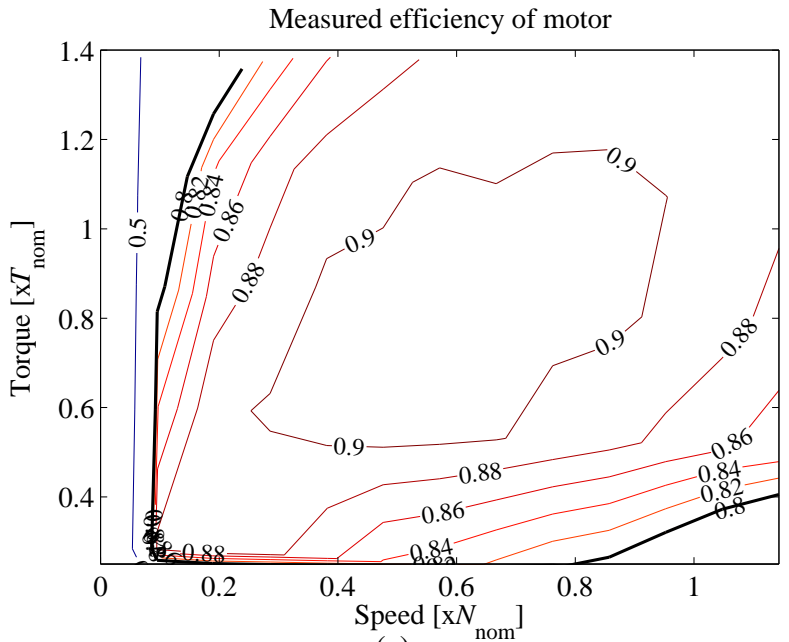

(a)

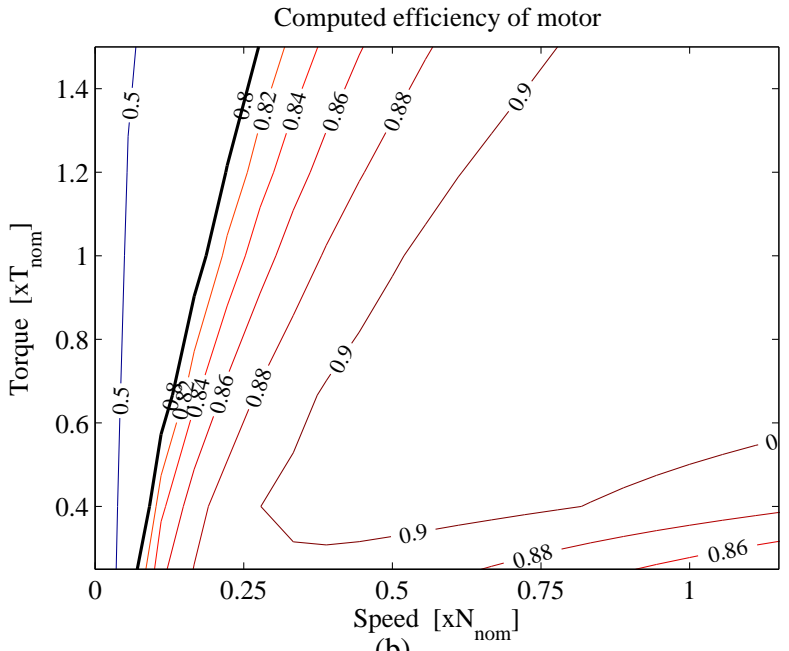

(b)

Fig. 10. Experimental machine with $t_{\mathrm{m}}=3.55 \mathrm{~mm}$ and M330-35A: (a) Measured efficiency map (b) Computed efficiency map via FEM. For clarity of the figure, the contour lines are not equidistant below efficiency 0.8 .

\section{EFFICIENCY IN FUNCTION OF MAGNET THICKNESS}

\section{A. The number of rotor poles and stator slots}

For fractional-slot machines with several combinations of number of poles and number of stator slots, the influence of the magnet thickness is investigated.

The star of slots theory is used to determine how to assign the several concentrated stator windings to the three phases: Fig. 11 shows the 8 combinations that were studied.

The rotor back iron thickness is computed as in Appendix 1 , and varies between $1.3 \mathrm{~mm}$ for the 16 pole machine to $3.2 \mathrm{~mm}$ for the 6 pole machine. In case of a high number of poles, the rotor yoke becomes thinner. This is quickly limited by the fact that a minimum rotor back iron thickness is needed for rotor structural integrity. In order to deal with this fact, a minimum thickness of $1.3 \mathrm{~mm}$ was set: see constraints in the methodology in section III. Furthermore, the rotor has in axial direction - next to the $40 \mathrm{~mm}$ magnet length - an additional
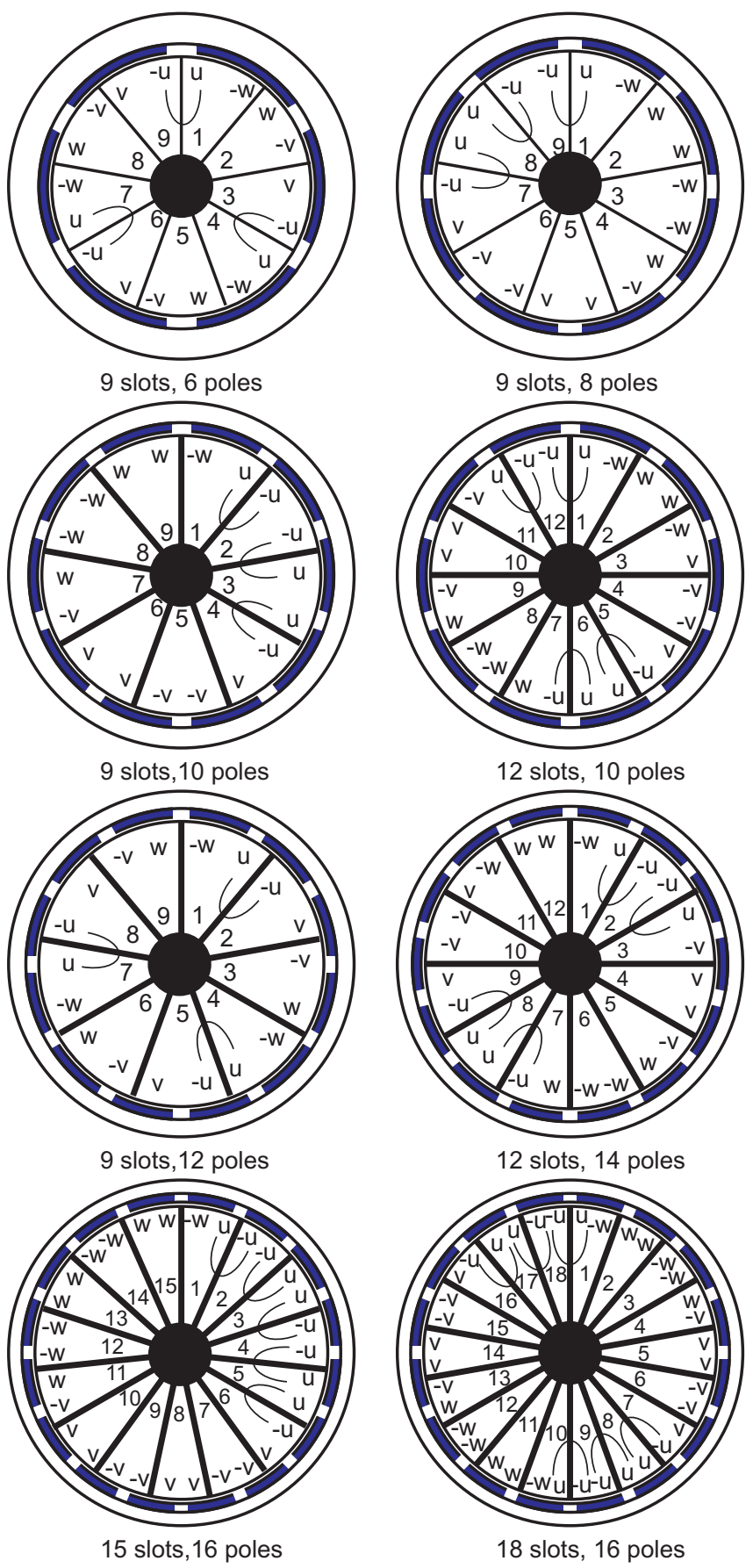

Fig. 11. Several combinations of number of poles and number of stator slots, showing the arrangement of phases in the stator slots as found by the star-of-slots method. The thick lines in the stator represent the stator teeth (not on scale). The wire connections are shown for phase $\mathrm{u}$. The rotor yoke thickness decreases with increasing pole number.

$20 \mathrm{~mm}$ long zone ( $L_{\mathrm{se}}$ in Table I). This extra region has a large amount of structural material in order to guarantee the structural integrity of the rotor. The experimental machine has a rotor yoke thickness of $1.6 \mathrm{~mm}$ and has no structural problems in the considered speed and torque range.

Fig. 12 shows the average efficiency for all 8 combinations of Fig. 11, and Table II gives the details for machines with all 8 combinations and a magnet thickness of $1.5 \mathrm{~mm}$. As already seen from Fig. $7 \mathrm{a}$, the combination $2 p=12, N_{\mathrm{t}}=9$ is 
optimal. This combination keeps a high efficiency regardless of $t_{\mathrm{m}}$. Other combinations have a slightly lower efficiency for small $t_{\mathrm{m}}$ and a dramatically lower efficiency for large $t_{\mathrm{m}}$. The reason is that configurations with small $p$ and thick magnets have a very small available section for the copper windings (small stator outer radius and thick stator teeth), resulting in a high phase resistance $R_{\mathrm{ph}}$ and huge average copper losses $P_{\text {cu,av }}$ : see Table II. These losses are averaged over a speed range $0.25-1.50 \times N_{\text {nom }}$ and torque range $0.25-1.50 \times T_{\text {nom }}$. Although the average iron losses $P_{\mathrm{fe}, \text { av }}$ are very small because of the low electrical frequency in case of low $p$, the average efficiency and especially the efficiency at high load torque are low. For configurations with high $p$, the average iron loss increases while the copper loss does not decrease compared to the machine with optimal combination of number of poles and number of stator slots.

TABLE II

Properties, AVERAge LOSSES AND AVERAGE EFFICIENCY $\eta_{\text {av }}$ OF THE BRUSHLESS MOTORS CORRESPONDING WITH THE 8 COMBINATIONS OF

$\left(2 p-N_{\mathrm{t}}\right)$ IN FIG. 11 , FOR A MAGNET THICKNESS $t_{\mathrm{m}}$ OF $1.5 \mathrm{MM}$

\begin{tabular}{lrrrrrrrr}
\hline & $6-9$ & $8-9$ & $10-9$ & $10-12$ & $12-9$ & $14-12$ & $16-15$ & $16-18$ \\
\hline $2 p$ & 6 & 8 & 10 & 10 & 12 & 14 & 16 & 16 \\
$r_{\text {so }}[\mathrm{mm}]$ & 32.7 & 33.9 & 34.6 & 34.6 & 35.1 & 35.5 & 35.8 & 35.8 \\
$w_{\text {tooth }}[\mathrm{mm}]$ & 11.1 & 11.2 & 9.1 & 8.7 & 5.9 & 6.3 & 5.8 & 5.7 \\
$N_{\mathrm{t}}$ & 9 & 9 & 9 & 12 & 9 & 12 & 15 & 18 \\
$N_{\mathrm{w}}$ & 19 & 17 & 16 & 13 & 17 & 12 & 10 & 8 \\
$w_{\mathrm{m}}[\mathrm{mm}]$ & 32.4 & 25.1 & 20.5 & 20.5 & 17.3 & 15.0 & 13.2 & 13.2 \\
$t_{\mathrm{yr}}[\mathrm{mm}]$ & 5.3 & 4.1 & 3.3 & 3.3 & 2.8 & 2.4 & 2.2 & 2.2 \\
\hline$R_{\mathrm{ph}}[\mathrm{m} \Omega]$ & 306 & 219 & 126 & 186 & 91.2 & 87.2 & 101 & 113 \\
$P_{\mathrm{cu}, \text { av }}[\mathrm{W}]$ & 123.9 & 88.6 & 51.2 & 75.4 & 37.0 & 35.3 & 41.2 & 46.0 \\
$P_{\text {fe, av }}[\mathrm{W}]$ & 10.8 & 18.1 & 26.8 & 24.8 & 31.8 & 45.6 & 53.7 & 51.5 \\
$\eta_{\text {av }}$ & 0.891 & 0.910 & 0.931 & 0.914 & 0.938 & 0.928 & 0.916 & 0.914 \\
\hline & & & & & & & & \\
\hline
\end{tabular}

Concerning the number of poles and stator slots, an important remark has to be made about unbalanced magnetic pull (UMP): see [30]. The machines with $2 p-N_{\mathrm{t}}= \pm 1$ have a large unbalanced magnetic pull. This UMP does not affect the efficiency, but it may cause mechanical vibrations. Nevertheless, [31] shows for a machine with 16 poles and 15 stator slots that machines with UMP can function properly.

\section{B. Soft magnetic material grade}

Four materials are considered: M235-35A, M250-50A, M330-35A and M600-50A. Table III in Appendix 2 gives the loss parameters and the maximal specific loss at $50 \mathrm{~Hz}$ and $1.5 \mathrm{~T}$.

It is evident that a low loss grade such as M235-35A (max. $2.35 \mathrm{~W} / \mathrm{kg}$ at $1.5 \mathrm{~T}$ and $50 \mathrm{~Hz}$ ) has lower losses than a high loss grade such as M600-50A. However, in spite of the lower specific loss, the M250-50A results in lower efficiency than the M330-35A, because of the high nominal frequency (e.g. 450 $\mathrm{Hz}$ if $2 p=12$ ). The M250-50A material has low hysteresis loss, but a higher dynamic loss due to the sheet thickness of $0.50 \mathrm{~mm}$. The M330-35A has a higher hysteresis loss, but its lower dynamic loss makes it more interesting at high frequency.

The optimal number of rotor poles depends on the soft magnetic material. In the legend of Fig. 7, it can be seen that the optimal number of stator slots and rotor poles is not
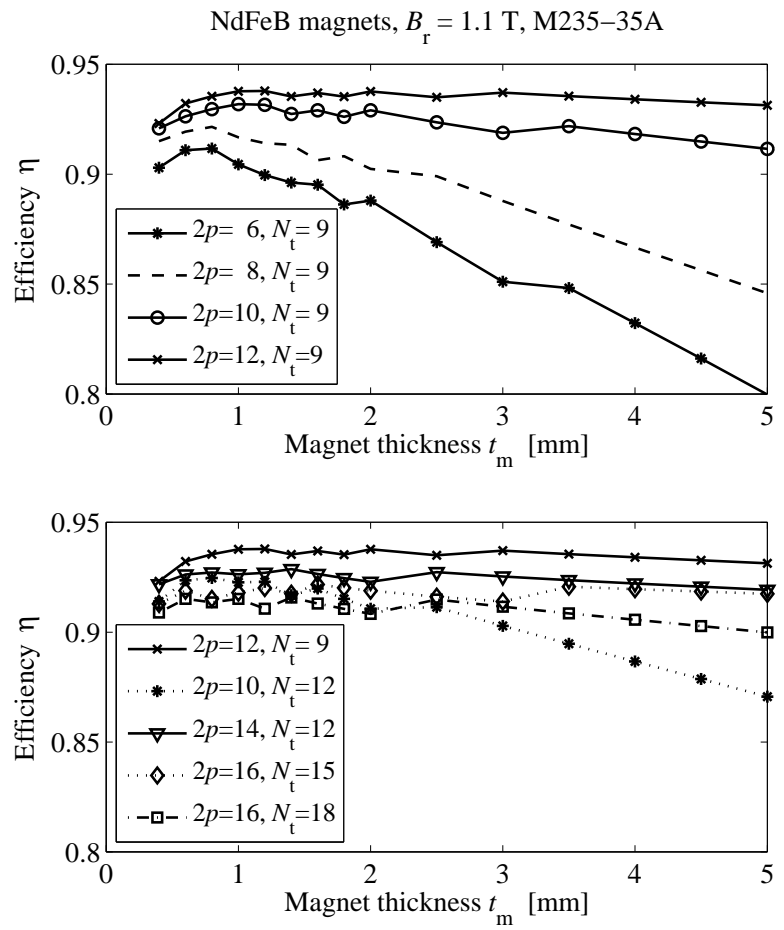

Fig. 12. Average efficiency as a function of the magnet thickness, for machines with different combinations of number of poles $2 p$ and number of stator slots $N_{\mathrm{t}}$. The machines with $2 p-N_{\mathrm{t}}= \pm 1$ have a large unbalanced magnetic pull [30]. The upper figure compares all combination with 9 stator slots. The lower figure shows the other combinations and the optimal one: $2 p=12, N_{\mathrm{t}}=9$. For $t_{\mathrm{m}}=1.5 \mathrm{~mm}$, the properties of these machines are given in table II. All machines have the same nominal voltage, current and output power.

the same for each material. The figure displays - for a given magnetic material and a given magnet thickness - the most energy efficient configuration out of the 8 machine types in Fig. 11. For all materials except the highest loss grade, the machine with 12 poles and 9 slots seems to be optimal. For the high loss material M600-50A however, the configurations with less poles $(2 p=10)$ turn out to have more efficiency, especially for small magnet thickness. The reason is the lower electrical frequency in order to avoid a huge iron loss.

Concerning the relationship between magnet thickness and soft magnetic material, an important conclusion is that the range of suitable magnet thicknesses is the same for all considered soft magnetic materials, and that the magnetic material grade influences the efficiency more than the magnet thickness for the considered machines and materials.

\section{Demagnetization risk and short circuit current}

The risk of demagnetization occurs for peak current and magnets at their maximal operating temperature. The analytical model predicts the demagnetization risk in the following way. The tangential peak magnetic field value is computed based on the peak mmf in a slot: $m m f_{\mathrm{p}}=2 I_{\mathrm{p}} N_{\mathrm{w}}$. The factor 2 is because of the two-layer winding. With a slot opening width $g_{\mathrm{d}}$, the peak magnetic field in the slot opening will be:

$$
H_{\mathrm{p}}=m m f_{\mathrm{p}} / g_{\mathrm{d}}
$$


If this peak value is higher than the magnetic field that causes irreversible demagnetization of the $\mathrm{NdFeB}$ magnets at operating temperature, the demagnetization risk is high. Notice that it is a worst case situation because the field seen by the magnet will be lower than the field in the slot opening. We illustrate the demagnetization risk for on the one hand a peak current which is 3 times the nominal current, and on the other hand for the short circuit current at nominal speed. The short circuit current can be computed based on the Emf, the stator resistance and inductance of the machine. The inductance is computed by well-known analytical expressions, for each configuration in Fig. 11.

Fig. 13 shows for which machines $H_{\mathrm{p}}$ is higher than the maximal $H$ of the magnets, which is $647 \mathrm{kA} / \mathrm{m}$ ( $8 \mathrm{kOersted})$ for $42 \mathrm{SH}$ magnets at $150^{\circ} \mathrm{C}$. It can be seen that only for the thinnest magnets a risk occurs for a given peak current $I_{\mathrm{p}}=3 I_{\text {nom }}$, at maximal magnet temperature. However, when considering the short circuit current, the situation is different: the short circuit current is much higher for high $t_{\mathrm{m}}$. This is caused by a lower number of stator turns, resulting in much lower impedance at nominal speed. Nevertheless, the leakage permeance and the peak mmf are not much influenced by the magnet thickness: thin magnets result in a bit more leakage field to the rotor yoke, and by consequence a somewhat higher demagnetization risk in thin magnets. For the considered combinations of number of poles and number of stator slots, the combinations with low number of poles and slots seem to be a bit more sensitive to demagnetization, and the risk is not much dependent on the magnet thickness.

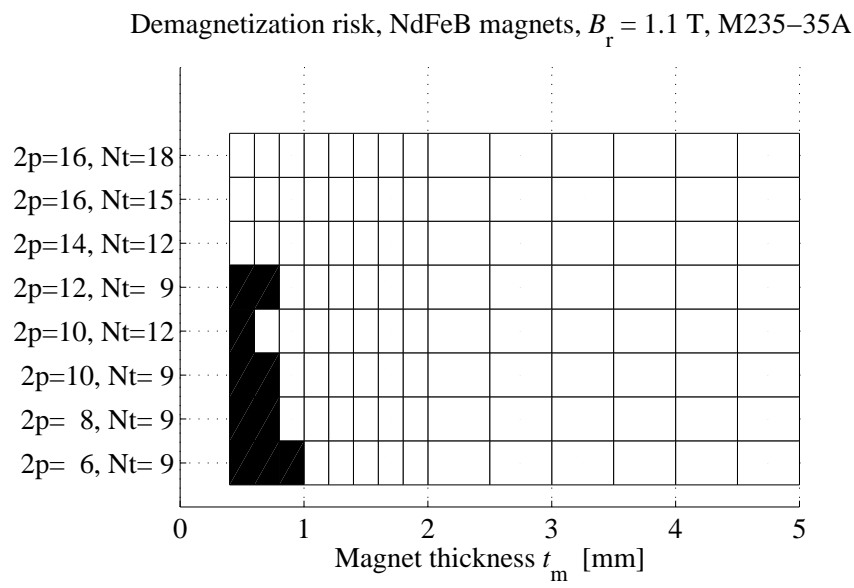

Fig. 13. Local demagnetization risk at a peak current of $I_{\mathrm{p}}=3 I_{\mathrm{nom}}$ as a function of the magnet thickness, for machines with different combinations of number of poles $2 p$ and number of stator slots $N_{\mathrm{t}}$.

\section{Torque ripple}

The torque ripple was computed by FEM, for several stator currents, as a function of the magnet thickness: Fig. 14. For example, the machine with 14 poles and 12 slots has a cogging torque periodicity of 30 electrical degrees, which can be seen on the torque waveform for very low current. For higher current, the torque ripple increases in amplitude. However, the magnet thickness seems to have almost no effect on the torque ripple for a given current.

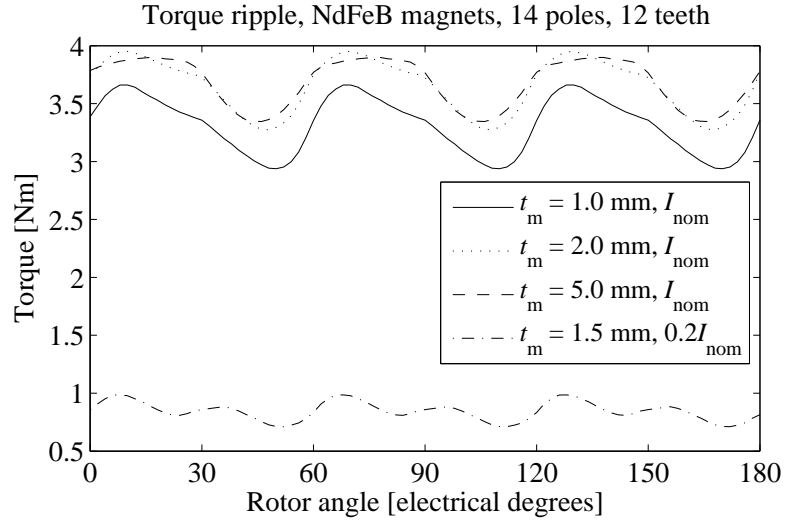

Fig. 14. Torque as a function of the rotor position for several magnet thicknesses and stator currents

\section{E. Ferrite magnets instead of rare earth magnets}

As a function of the thickness of the ferrite magnets, Fig. 15 shows the average efficiency for different material grades, computed by the analytical model. The nominal power was reduced from 1500 to $750 \mathrm{~W}$, because for $1500 \mathrm{~W}$, the losses would be too high to allow sufficient cooling [13]. In spite of the lower nominal power, the optimal efficiency is still lower than for $\mathrm{NdFeB}$ and is obtained for $t_{\mathrm{m}} \geq 2 \mathrm{~mm}$, much more than for $\mathrm{NdFeB}$ magnets $\left(t_{\mathrm{m}} \geq 1 \mathrm{~mm}\right)$. This is logic because the flux density level is much lower. Nevertheless, the advantages of ferrite magnets are the price and a lower specific weight. The lower flux density level causes much thinner stator teeth, stator yoke and rotor yoke. The copper area is larger than for $\mathrm{NdFeB}$ magnets. A disadvantage of the thicker magnets is that the air gap diameter is reduced because the outer machine diameter is fixed. For M250-50A material and $3 \mathrm{~mm}$ thick magnets, the average efficiency is $91 \%$, significantly lower than the almost $93 \%$ with $\mathrm{NdFeB}$ magnets (both found by the analytical model). Although Fig. 15 includes magnets of less than $1 \mathrm{~mm}$ thickness, it is recommended to use thicker ferrite magnets to avoid the risk of demagnetization. Also, engineering practice and experience show that it is impossible to use in electrical machines magnets with radial thickness of $1 \mathrm{~mm}$ or smaller.

\section{CONCLUSION}

Outer rotor permanent magnet machines can be made with magnets in a quite large thickness range without significantly decreasing the efficiency or the torque density. Evidently, the geometry of the machine should be designed for the chosen amount of magnets. A low loss soft magnetic material is much more important to have good efficiency than sufficiently thick magnets: up to $5 \%$ difference in average efficiency between the lowest and the highest loss grade. The PWM loss is not negligible in the stator iron, but almost independent of the magnet thickness. In the rotor, the PWM loss is the dominant loss term; it has a maximum for a magnet thickness of about 2-3 mm. For a given load and speed range, an optimal combination of number of poles and slots exists that is dependent on the soft magnetic material grade but not on the magnet thickness; for non-optimal combinations, the average 
efficiency decreases significantly especially in case of thick magnets. Some combinations suffer from demagnetization risk, but several other combinations don't have this risk even for small magnet thickness. The torque ripple depends on the current, but almost not on the magnet thickness. With ferrite magnets, the average efficiency is much lower than with $\mathrm{NdFeB}$ magnets, making it difficult to keep a similar nominal power. If the nominal power is reduced by a factor 2 , the average efficiency is only $2 \%$ lower than with rare earth magnets.

\section{APPENDIX 1: ANALYTICAL MODEL}

1) The air gap flux density $B_{\mathrm{a}}(x)$ along the circumference is computed like in [20]. Alternatively, the more simple equation of [21] can be used that neglects rotor curvature. The rotor yoke thickness is determined from the maximum of the air gap flux density $B_{\mathrm{a}, \max }$ : $t_{\mathrm{ry}}=\frac{w_{\mathrm{m}}}{2} \frac{B_{\mathrm{a}, \max } L_{\mathrm{s}}}{B_{\mathrm{tm}}\left(L_{\mathrm{s}}+L_{\mathrm{se}}\right)}$, where $L_{\mathrm{se}}$ is the additional axial length available for the rotor flux.

2) The Emf per phase at $N_{\text {nom }}=60 \Omega_{\text {nom }} /(2 \pi)$ is based on the Emf of one side of a turn $E_{\mathrm{t}}=B_{\mathrm{a}, \max } r_{\mathrm{so}} \Omega_{\mathrm{nom}} L_{\mathrm{s}}$, taking into account the phase shift between several concentrated windings belonging to the same phase.

3) The width of the stator teeth $w_{\text {tooth }}$ is found from the total flux in a tooth and a peak flux density that is assumed to be $B_{\mathrm{tm}}=1.65 \mathrm{~T}$, a typical value for silicon steel laminations. The thickness of the tooth tips is chosen in the same way.

4) After the tooth geometry is chosen, the available space for the copper windings is computed. The number of turns is determined by dividing the nominal voltage by the Emf per turn. The wire diameter is determined from the fill factor (Table I), the number of turns and the available space for the copper windings. After estimating the end turn length, the resistance per phase $R_{\mathrm{ph}}$ is computed.

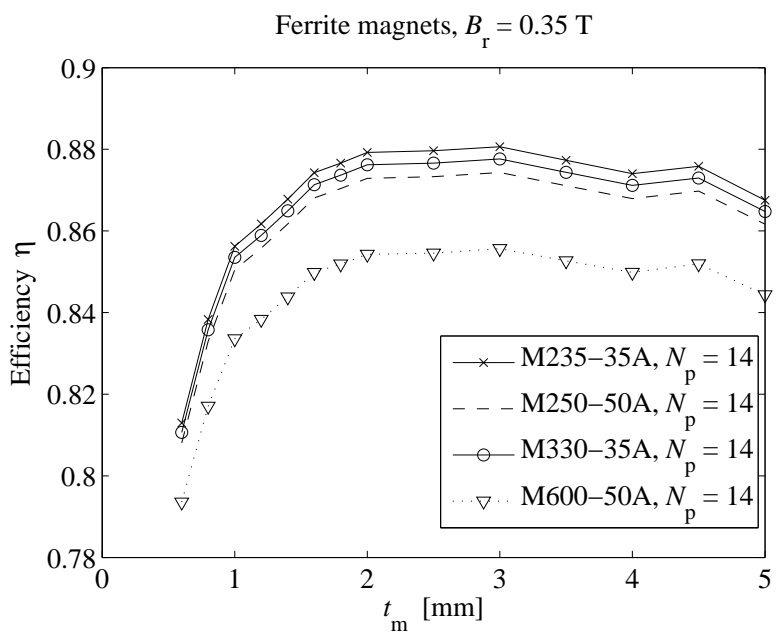

Fig. 15. Average efficiency of a PMSM in the speed range $0.25-1.50 \times N_{\text {nom }}$ and torque range $0.25-1.50 \times T_{\text {nom }}$, as a function of the ferrite magnet thickness $t_{\mathrm{m}}$ and the material grade. The number of poles is the one that results in the highest efficiency. The figure is obtained by the analytical model.
5) The copper loss $P_{\mathrm{cu}}$ is found as a function of the load factor $L F$. Here $L F=1$ denotes the nominal load or torque of the machine and $P_{\text {nom }}$ is the nominal power.

$$
P_{\mathrm{cu}}(L F)=3 R I^{2} \text { with } I=\sqrt{\frac{2}{3}} \frac{P}{V_{\mathrm{dc}}}=\sqrt{\frac{2}{3}} \frac{L F P_{\mathrm{nom}}}{V_{\mathrm{dc}}}
$$

6) The efficiency is found as a function of the load factor and the relative speed $N$

$$
\eta(N, L F)=\frac{P_{\mathrm{m}}(N, L F)}{P_{\mathrm{m}}(N, L F)+P_{\mathrm{cu}}(L F)+P_{\mathrm{fe}}(N)}
$$

where $P_{\mathrm{m}}$ is the mechanical power.

\section{APPENDIX 2: IRON LOSS MODEL}

Hysteresis loops were measured on Epstein frame between $0.1 \mathrm{~T}$ and $1.8 \mathrm{~T}$, under sinusoidal flux density waveform and at frequencies of $10,15,25,50,100,200,400,700 \mathrm{~Hz}$, and quasi-static. First, in (1), the coefficients $a$ and $\alpha$ of the hysteresis loss are determined by solving a least squares problem based on the quasi-static measurements only. The classical loss coefficient $b$ is computed from the electrical conductivity $\sigma$, and the lamination thickness $t_{1}: b=\frac{\pi^{2}}{6} \sigma t_{1}^{2}$. The conductivity is in table III. The excess loss coefficients $c$ and $d$ are fitted based on the measurements at the above mentioned frequencies between $10 \mathrm{~Hz}$ and $700 \mathrm{~Hz}$ : table III.

The same procedure is repeated for the time domain loss model, giving rise to different coefficients.

TABLE III

LOSS RELATED PROPERTIES OF MAGNETIC MATERIAL GRADES IN EQ. (1)

\begin{tabular}{lrrrr}
\hline & M235-35A & M250-50A & M330-35A & M600-50A \\
\hline$a$ & 0.0179 & 0.0140 & 0.0223 & 0.0353 \\
$\alpha$ & 2.000 & 1.950 & 2.000 & 1.789 \\
$b$ & $4.70 \mathrm{e}-5$ & $9.44 \mathrm{e}-5$ & $6.31 \mathrm{e}-5$ & $1.829 \mathrm{e}-4$ \\
$c$ & 0.108 & 0.00538 & 0.126 & 0.2019 \\
$d$ & 0.00050 & 0.035 & 0.00033 & $3.693 \mathrm{e}-4$ \\
$t_{l}$ & $0.35 \mathrm{~mm}$ & $0.50 \mathrm{~mm}$ & $0.35 \mathrm{~mm}$ & $0.50 \mathrm{~mm}$ \\
$\sigma$ & $1.70 \mathrm{MS} / \mathrm{m}$ & $1.70 \mathrm{MS} / \mathrm{m}$ & $2.28 \mathrm{MS} / \mathrm{m}$ & $3.24 \mathrm{MS} / \mathrm{m}$ \\
$P_{\text {spec }}$ & $2.35 \mathrm{~W} / \mathrm{kg}$ & $2.50 \mathrm{~W} / \mathrm{kg}$ & $3.30 \mathrm{~W} / \mathrm{kg}$ & $6.00 \mathrm{~W} / \mathrm{kg}$ \\
\hline
\end{tabular}

\section{REFERENCES}

[1] A.M. El-Refaie, "Fractional-slot concentrated windings synchronous permanent magnet machines: opportunities and challenges," IEEE Trans. Power Electronics, Vol. 57, No. 1, pp. 107-121, Jan 2010.

[2] D.G. Dorrell, M.F. Hsieh, M. Popescu, L. Evans, D.A. Staton, and V. Grout, "A Review of the Design Issues and Techniques for Radial-Flux Brushless Surface and Internal Rare-Earth Permanent-Magnet Motors," IEEE Trans. Ind. Electron., Vol. 58, No. 9, pp. 3741-3757, Sep. 2011.

[3] J. Cros and P. Viarouge, "Synthesis of high performance PM-motors with concentrated windings," IEEE Trans. Energy Convers., Vol. 17, No. 2, pp. 248-253, Jun. 2002.

[4] N. Bianchi, S. Bolognani, and G. Grezzani, "Design considerations for fractional-slot winding configurations of synchronous machines," IEEE Trans. Ind. Appl., Vol. 42, No. 4, pp. 997-1006, Jul./Aug. 2006.

[5] A. Di Gerlando, R. Perini, and M. Ubaldini, "High pole number PM synchronous motor with concentrated coil armature windings," Proc. ICEM 2004, Cracow, Poland, 5-8 Sept. 2004, Paper 58.

[6] N. Bianchi, S. Bolognani, and E. Fornasiero, "A general approach to determine the rotor losses in three-phase fractional-slot PM machines," in Proc. IEEE IEMDC, 2007, vol. 1, pp. 634-641. 
[7] H. Polinder, M. J. Hoeijmakers, and M. Scuotto, "Eddy-current losses in the solid back-iron of permanent-magnet machines with concentrated fractional pitch windings," in Proc. 3rd IET Int. Conf. Power Electron.,Mach., Drives, pp. 479-483, Mar. 2006.

[8] K. Atallah, D. Howe, P. H. Mellor, and D. A. Stone, "Rotor loss in permanent-magnet brushless AC machines," IEEE Trans. Ind. Appl., vol. 36, no. 6, pp. 1612-1618, Nov./Dec. 2000.

[9] J. Ede, K. Atallah, G. Jewell, J. Wang and D. Howe, "Effect of Axial Segmentation of Permanent Magnets on Rotor Loss in Modular Permanent-Magnet Brushless Machines," IEEE Trans. Ind. Appl., Vol. 43, No. 5, pp. 1207-1213, Sept. 2007.

[10] R.P. Praveen, M.H. Ravichandran, V.T. Sadasivan Achari, V.P. Jagathy Raj, G. Madhu, and G.R. Bindu, "A Novel Slotless Halbach-Array Permanent-Magnet Brushless DC Motor for Spacecraft Applications," IEEE Trans. Ind. Electron., Vol. 59, No. 9, pp. 3553 - 3560, Sep. 2012.

[11] D.G. Dorrell, A.M. Knight, L. Evans, and M. Popescu, "Analysis and Design Techniques Applied to Hybrid Vehicle Drive MachinesAssessment of Alternative IPM and Induction Motor Topologies,", IEEE Trans. Ind. Electron., Vol. 59, No. 10, pp. 3690 -3699, 2012.

[12] W. Cao, B.C. Mecrow, G.J. Atkinson, J.W. Bennett, and D.J. Atkinson, "Overview of Electric Motor Technologies Used for More Electric Aircraft (MEA)," IEEE Trans. Ind. Electron., Vol. 59, No. 9, pp. 3523 - 3531, Sep. 2012.

[13] P. Sergeant, and A. Van den Bossche, "Reducing the permanent magnet content in fractional-slot concentrated-windings permanent magnet synchronous machines," International Conference on Electrical Machines (ICEM), Marseille, France, 2-5 September, 2012, pp. 1403-1409, paper FF-001201.

[14] G. R. Slemon, "On the design of high-performance surface-mounted PM motors,", IEEE Trans. Ind. Appl., Vol. 30 , No 1, pp. 134-140, 1994.

[15] A. Tariq, C. Nino-Baron, and E. Strangas, "Iron and Magnet Losses and Torque Calculation of Interior Permanent Magnet Synchronous Machines Using Magnetic Equivalent Circuit," IEEE Trans. Magn., Vol. 46, No. 12, pp. 4073-4080, Dec. 2010.

[16] T. Lubin, S. Mezani, and A. Rezzoug, "2-D Exact Analytical Model for Surface-Mounted Permanent-Magnet Motors With Semi-Closed Slots IEEE Trans. Magn., Vol. 47, No. 2, pp.479-492, Feb. 2011.

[17] G. Pellegrino, A. Vagati, P. Guglielmi, B. Boazzo, "Performance Comparison Between Surface-Mounted and Interior PM Motor Drives for Electric Vehicle Application," IEEE Trans. Ind. Electron., Vol. 59, No. 2, pp. 803-811, Feb. 2012.

[18] A. Di Gerlando, G. Foglia, M.F. Iacchetti, and R. Perini, "Axial Flux PM Machines With Concentrated Armature Windings: Design Analysis and Test Validation of Wind Energy Generators," IEEE Trans. Ind. Electron., Vol. 58, No. 9, pp. 3795-3805, Sep. 2011.

[19] Z.R. Zhang, Y.G. Yan, S.S. Yang, and Z. Bo, "Development of a New Permanent-Magnet BLDC Generator Using 12-Phase Half-Wave Rectifier,' IEEE Trans. Ind. Electron., Vol. 56, No. 6, pp. 2023-2029, Jun. 2009.

[20] S.R. Holm, H. Polinder, J.A. Ferreira, "Analytical modeling of a permanent-magnet synchronous machine in a flywheel," IEEE Trans. Magn., Vol. 43, No. 5, pp. 1955-1967, May 2007.

[21] M. J. Chung and D. G. Gweon, "Modeling of the armature slotting effect in the magnetic field distribution of a linear permanent magnet motor," Electrical Engineering, Vol. 84, pp. 101-108, 2002.

[22] L.J. Wu, Z.Q. Zhu, D.A. Staton, M. Popescu, and D. Hawkins, "Comparison of Analytical Models of Cogging Torque in Surface-Mounted PM
Machines," IEEE Trans. Ind. Electron., Vol. 59, No. 6, pp. 2414-2425, Jun. 2012.

[23] E. Barbisio, F. Fiorillo, and C. Ragusa, "Predicting loss in magnetic steels under arbitrary induction waveform and with minor hysteresis loops," IEEE Trans. Magn., Vol. 40, pp. 1810-1819, Jul. 2004.

[24] K. Yamazaki, and A. Abe, "Loss Investigation of Interior PermanentMagnet Motors Considering Carrier Harmonics and Magnet Eddy Currents," IEEE Trans. Ind. Appl., Vol. 45, No. 2, pp. 659-665, Mar. 2009.

[25] A. Boglietti, A. Cavagnino, "Iron loss prediction with PWM supply: An overview of proposed methods from an engineering application point of view," Electric Power Systems Research, Vol. 80, pp. 11211127, 2010.

[26] A. Boglietti, P. Ferraris, M. Lazzari, M. Pastorelli, "Influence of modulation techniques on iron losses with single phase DC/AC converter," IEEE Trans. Magn., Vol. 32, No. 5, pp. 48844886, Sep. 2005.

[27] Z. Gmyrek, and J. Anuszczyk, "The power loss calculation in the laminated core under distorted flux conditions," International Conference on Electrical Machines, ICEM2004, Cracow, Poland, 2004, CD-ROM.

[28] J. Alexandrova, H. Jussila, J. Nerg, J. Pyrhönen, "Comparison Between Models for Eddy-Current Loss Calculations in Rotor Surface-Mounted Permanent Magnets," Proc. ICEM 2010, 6-8 Sept. 2010, Rome, Italy.

[29] A.Jassal, H. Polinder, D. Lahaye, J.A.Ferreira, "Comparison of Analytical and Finite Element Calculation of Eddy-Current Losses in PM Machines," Proc. ICEM 2010, 6-8 Sept. 2010, Rome, Italy.

[30] D.G. Dorrell, M. Popescu, and D. Ionel, "Unbalanced Magnetic Pull Due to Asymmetry and Low-Level Static Rotor Eccentricity in FractionalSlot Brushless Permanent-Magnet Motors with Surface-Magnet and Consequent-Pole Rotors", IEEE Trans. Magn., Vol. 46, No. 7, Jul. 2010.

[31] H. Vansompel, P. Sergeant, L. Dupre, and A. Van den Bossche, "Evaluation of Simple Lamination Stacking Methods for the Teeth of an Axial Flux Permanent-Magnet Synchronous Machine with Concentrated Stator Windings," IEEE Trans. Magn., Vol. 48, No. 2, pp. 999-1002, Feb. 2012.

Peter Sergeant received the M.Sc. degree in electromechanical engineering in 2001, and the Ph.D. degree in engineering sciences in 2006, both from Ghent University, Ghent, Belgium. In 2001, he became a researcher at the Electrical Energy Laboratory of Ghent University. He became a postdoctoral researcher at Ghent University in 2006 (postdoctoral fellow of the Research Foundation - Flanders) and at Ghent University College in 2008. Since 2012, he is associate professor at Ghent University and Ghent University College. His current research interests include numerical methods in combination with optimization techniques to design nonlinear electromagnetic systems, in particular, electrical machines for sustainable energy applications.

Alex P. M. Van den Bossche received the M.S. and the Ph.D. degrees in electromechanical engineering from Ghent University Belgium, in 1980 and 1990 respectively. He has worked there at the Electrical Energy Laboratory. Since 1993, he is a professor at the same university in the same field. His research is in the field of electrical drives, power electronics on various converter types and passive components and magnetic materials. $\mathrm{He}$ is also interested in renewable energy conversion. He is an author of the book "Inductors and transformers for power electronics". 